\title{
Heat transfer study of poly-c PV system integrated with phase change material under semi-arid area (Errachidia- Drâa Tafilalet)
}

\author{
Ibtissam Lamaamar ${ }^{2}$, Amine Tilioua ${ }^{1}$, Zaineb Benzaid ${ }^{1}$, Abdelouahed Ait Msaad ${ }^{2}$ and Moulay Ahmed Hamdi Alaoui ${ }^{3}$
}

${ }^{1}$ LM3ER, Department of physics Faculty of sciences and techniques, University Moulay Ismaïl, BP.509, Boutalamine Errachidia, Morocco

${ }^{2}$ LTI, Ecole Supérieure de Technologie de Fès, U.S.M.B.A, Route d'Imouzzer, BP 2427 Fez, Morocco

${ }^{3}$ LMM, Faculty of Sciences, University Moulay Ismaïl, Department of Physics, B.P. 11201 Zitoune 5000 Meknes, Morocco

\begin{abstract}
The high operating temperature of the photovoltaic (PV) modules decreases significantly its efficiency. The integration of phase change material (PCM) is one of the feasible techniques for reducing the operating temperature of the PV module. A numerical simulation of the PV module with PCM and without PCM has been realized. The thermal behavior of the PV module was evaluated at the melting and solidification processes of PCM. The results show that the integration of RT35HC PCM with a thickness of $4 \mathrm{~cm}$ reduces the temperature of the PV module by $8{ }^{\circ} \mathrm{C}$ compared to the reference module. Compared the RT35 and RT35HC, we found that the latent heat has a significant effect on the PCM thermal comportment. Furthermore, it has been found that the thermal resistance of the layers plays an important role to dissipate the heat from the PV cells to the PCM layer, consequently improving the heat transfer inside the PV/PCM system.
\end{abstract}

* Corresponding author : ibtissamlamaamar@gmail.com 


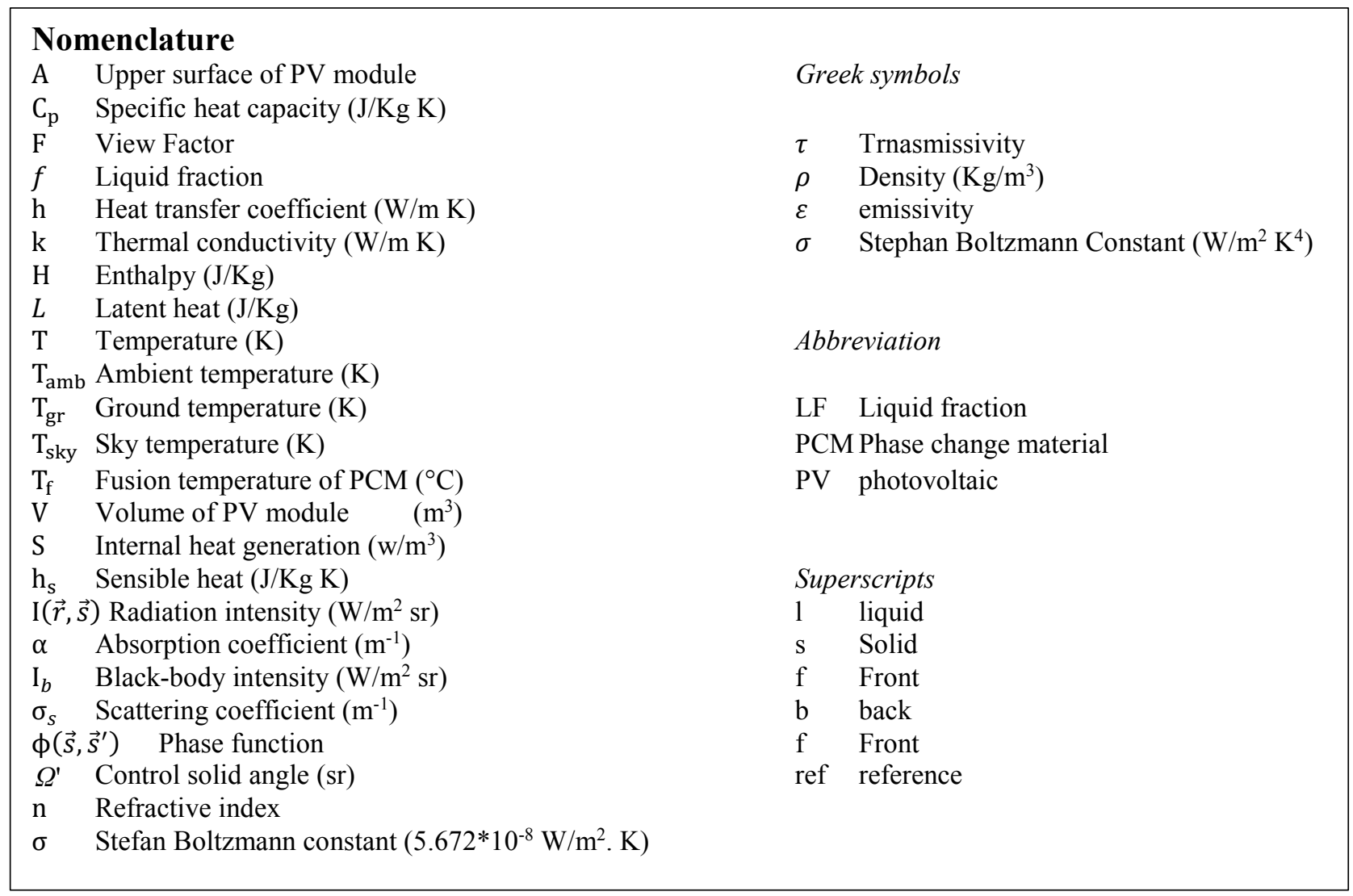

\section{Introduction}

The photovoltaic (PV) module can absorb up to $80 \%$ of incident solar radiation. A very small amount is transformed into electricity, while the rest is converted into heat, which increases the operating temperature of the PV module. The temperature remains one of the important parameters that can affect the PV cell performance. $\quad 1{ }^{\circ} \mathrm{C}$ increases in the PV panel temperature above $25^{\circ} \mathrm{C}$ leads to reduce the output power and conversion efficiency by $0.65 \%$ and $0.08 \%$ respectively [1], for a crystalline silicon PV operating above $25{ }^{\circ} \mathrm{C}$ typically, shows a temperature-dependent power decrease with a coefficient of $0.4 \% / \mathrm{K}$ [2]. Many studies have been interested to enhance the PV module performances by decreasing the PV module temperature. Zhou et al [3] studied the thermal behavior of the polycrystalline PV module, the authors showed that the performance of the PV modules can be improved by optimizing the back sheet, and the aluminum alloy sheet performed best on heat dissipation and the highest module temperature scarcely changed within proper scope of thickness, Moreover, several works focused on the different cooling technologies to decrease the PV module temperature operating and consequently increasing its performances. Elbreki et al [4] focused on passive and active heat dissipation approaches to define the range of temperature reduction that is possible. H.G. Teo et al [5] introduce the active cooling of the photovoltaic module, they concluded that without active cooling, the temperature of the module was high and the solar cells cannot reach an efficiency up to $9 \%$. However, when the module operated in an active cooling state, the temperature dropped significantly, which resulted in an increase of efficiency until 14\%. Likewise, Shukla et al [6] discussed various cooling techniques such as forced and natural air cooling, hydraulic, heat pipe cooling, cooling with phase change materials and thermoelectric cooling of photovoltaic panels. They claimed that the the integration of phase change material (PCM) as a cooling medium presents an alternative to the energy performance of the PV module. The heat being absorbed or returned during the transition from one state to another. In other research works [7], [8] the investigation and analysis of the available thermal energy storage systems incorporating PCMs for use in different applications; extensive efforts have been made to apply the latent heat storage method to solar energy systems [7]. In this sense, the authors agreed on the advantage of coupling the PCM to the PV modules. Four different $\mathrm{PV} / \mathrm{PCM}$ systems were tested under three insolation intensities to determine the performance of each PCM. Changing the mass of PCM and thermal conductivities of PCM and PV/PCM system has an effect on thermal regulation of the PV. A maximum temperature reduction of $18^{\circ} \mathrm{C}$ was achieved for $30 \mathrm{~min}$ while $10{ }^{\circ} \mathrm{C}$ temperature reduction was maintained for 5 $\mathrm{h}$ at $1000 \mathrm{~W} / \mathrm{m}^{2}$ insolation [2]. Browne et al [9] explained that the regulation of the PV systems temperature comprised of crystalline silicon cells appears to be the most economically viable for the use of $\mathrm{PV} / \mathrm{PCM}$ systems, as increases in temperature have the most detrimental effect on the efficiency of silicon 
solar cells compared to the organic or thin film cells. Similarly Ahmad et al [10] developed a PV/PCM system to reduce the $\mathrm{PV}$ panel temperature, the system has been evaluated outdoors with two PCMs in two different climates, they concluded that the PCMs attained higher temperature drop in warm and stable weather conditions of Vehari region than the cooler and variant weather conditions of Dublin. Kibria et al [11] developed an a transient one-dimensional energy balance model to examine the thermal performance of a PV module integrated with PCM storage system, the result indicates that the PCM are shown to be an effective means of limiting the temperature rise in the PV devices thus increasing the thermal performance up to $5 \%$. Further, research works has focused on numerical methods dealing with phenomena related to PCM. Voller [12][14] discussed the numerical method which can be used to simulate with PCM problems, an enthalpy method is developed for analysis of one-dimensional phase change problems under heat conduction [13]. He also develops a rapid implicit solution technique for the enthalpy formulation of conduction controlled phase change problems, and he provides an overview of the numerical methods that can be used to deal with non-linear phenomena associated with the solidification phase change processes. In the first case, he focused on the fixed and distorting grid solutions from Stefan problems, the discussion is extended to include fixed grid methods directed to more general phase change systems [14], a survey of phase change formulation reveals that the most common approach applied in the solution of phase change problems is the formulation using the enthalpy method [15].

In the present study, a two dimensional thermal model for polycrystalline silicon PV modules coupled with PCM was developed by finite volume method. Temperature evolution and its distribution throughout the layers of the PV module without and with PCM was discussed, effect of thickness and latent heat of the PCM was analysed.

\section{Materials and methods}

\subsection{System description}

The PV/PCM system consists of eight layers, the first six are the polycrystalline silicon photovoltaic (PV) module layers, followed by the PCM which is covered by aluminum sheet. The system is subject to variable meteorological conditions of the Er-rachidia region taken on June 25, 2020, as shown in Figure1. To study the heat transfer in the PV/PCM system, we took into account the convection and radiation exchanges on the two front and rear sides of the system and by conduction between layers of the PV/ PCM system. Figure 2 describes the heat exchanges on boundary conditions, PV module's layers and inclination. The height of the $\mathrm{PV} / \mathrm{PCM}$ system taken for this study is $0,1 \mathrm{~m}$. The PCM layer is $0.02 \mathrm{~m}$ thick, filled in an aluminum container $0.002 \mathrm{~m}$ thick.

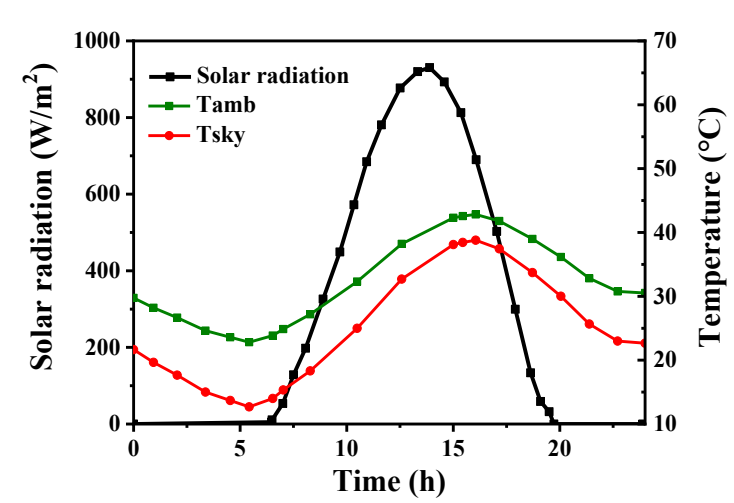

Figure 1. Solar radiation, ambient temperature and sky temperature variation for 25 June 2020

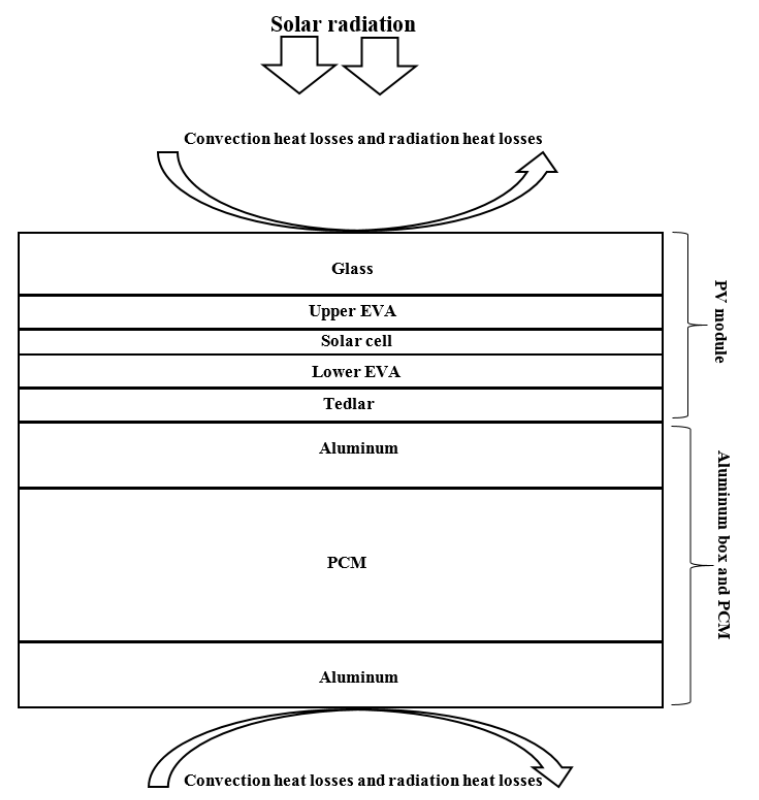

Figure 2. Physical model and heat transfer energy exchange of the PV/PCM system

The thermo-physical and optical properties of the PV module layers are listed in Table 1 and Table 2 and the thermo-physical commercial PCMs used in this work are listed in Table 3.

The thermodynamic study of PV module coupled with PCM has been performed using volume finite analysis approach with Ansys fluent software. The simulation was based on a two-dimensional model, using the following simplified assumptions:

- Thermal properties of all materials in the module were presumed to be isotropic and temperatureindependent.

- The model sides was taken to be adiabatic.

- Solar radiation which was neither reflected nor converted to electricity became thermal energy.

- The back and the front of the PV module were taken to view the ground and sky respectively.

- There is not any agent deposited on the PV surface affecting the absorptivity of the PV module. 
Table 1. Optical proprieties of PV module layers

\begin{tabular}{|l|l|l|l|l|}
\hline $\begin{array}{l}\text { Material's } \\
\text { layers }\end{array}$ & $\begin{array}{l}\text { Reflecti } \\
\text { vity }\end{array}$ & $\begin{array}{l}\text { Absorpt } \\
\text { ivity }\end{array}$ & $\begin{array}{l}\text { Transiti } \\
\text { vity }\end{array}$ & $\begin{array}{l}\text { Emiss } \\
\text { ivity }\end{array}$ \\
\hline Glass & 0.04 & 0.04 & 0.92 & 0.85 \\
\hline EVA & 0.02 & 0.08 & 0.9 & - \\
\hline $\begin{array}{l}\text { Polycrystallin } \\
\text { e silicon }\end{array}$ & 0.08 & 0.9 & 0.02 & - \\
\hline Tedlar & 0.086 & 0.128 & 0.012 & 0.92 \\
\hline
\end{tabular}

Table 2. Thermo-physical proprieties of PV module layers

\begin{tabular}{|l|l|l|l|l|}
\hline $\begin{array}{l}\text { Material's } \\
\text { layers }\end{array}$ & $\begin{array}{l}\text { Density } \\
\left(\mathrm{kg} / \mathrm{m}^{3}\right)\end{array}$ & $\begin{array}{l}\text { Specific } \\
\text { heat } \\
(\mathrm{J} / \mathrm{kg} \mathrm{K})\end{array}$ & $\begin{array}{l}\text { Thermal } \\
\text { conductiv } \\
\text { ity }(\mathrm{W} / \mathrm{m} \\
\mathrm{K})\end{array}$ & $\begin{array}{l}\text { Thickne } \\
\mathrm{ss}(\mathrm{m})\end{array}$ \\
\hline Glass & 3000 & 500 & 1.8 & 0.003 \\
\hline EVA & 960 & 2090 & 0.35 & 0.0005 \\
\hline $\begin{array}{l}\text { Polycryst } \\
\text { alline } \\
\text { silicon }\end{array}$ & 2330 & 677 & 148 & 0.0003 \\
\hline Tedlar & 1200 & 1250 & 0.2 & 0.0005 \\
\hline
\end{tabular}

Table 3. Optical proprieties of PCM

\begin{tabular}{|l|l|l|}
\hline PCMs & RT35HC & RT44HC \\
\hline Melting temperature $\left({ }^{\circ} \mathrm{C}\right)$ & 35 & 44 \\
\hline Density $\left(\mathrm{kg} / \mathrm{m}^{3}\right)$ & $880 \mathrm{~s} / 7701$ & $800 \mathrm{~s} / 7001$ \\
\hline Specific heat $(\mathrm{J} / \mathrm{kg} \mathrm{K})$ & 2000 & 2000 \\
\hline Latent heat & 240000 & 250000 \\
\hline $\begin{array}{l}\text { Thermal conductivity }(\mathrm{W} / \mathrm{m} \\
\mathrm{K})\end{array}$ & 0.2 & 0.2 \\
\hline
\end{tabular}

\subsection{Theoretical analysis}

\subsubsection{Energy equation for solid part}

Within the layers of the PV module, the dominant transfer mode is conduction. Consequently, the applied heat transfer equation by diffusion, after simplifications, is expressed by the following equation:

$$
\rho C_{p} \frac{\partial T}{\partial t}=k\left(\frac{\partial^{2} T}{\partial^{2} x}+\frac{\partial^{2} T}{\partial^{2} y}\right)+S_{i}
$$

\subsubsection{Radiation Heat transfer}

The incident radiation $\mathrm{I}(\mathrm{t})$, after falling on the glass which is a semi-transparent medium, a part of this radiation is absorbed through the thickness of the layer of the glass, another part is reflected, and the remaining part passes through the glass and be transmitted to adjacent layers. Figure 3 represent distribution of the radiation flux falling on the glass. The sum of the three radiations, that absorbed, transmitted and reflected would be equal to the incident radiation. Different works have focused their research on the distribution of radiation in a semi-transparent medium [16], [17], and discrete ordinate (DO) model is one of models solves radiative heat transfer problems involving semitransparent media. In this work, we implement DO model in FLUENT, which uses a conservative finitevolume approach and which will be discuss in the section below.

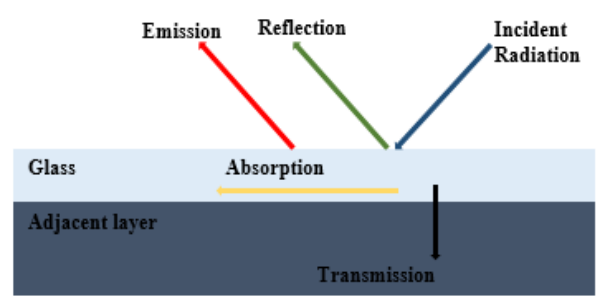

Figure 3. Distribution of the radiation flux falling on the semi-transparent layer (Glass)

\subsubsection{Discrete ordinate method}

Discrete ordinate (DO) model solves radiative transfer equation (RTE) for discrete solid angle. The implementation of DO model in FLUENT uses a conservative finite volumes approach. DO model is a comprehensive radiation model that can account for most radiation problems [18]. RTE was developed to describe the steady state conservation of radiant energy of a single ray traveling in direction $\mathrm{S}$ from position $\mathrm{r}$. RTE equation is shown below with parts of the equation labeled to provide references for the detailed description to follow:

$$
\begin{aligned}
& \frac{d I(\vec{r}, \vec{s})}{d s}=a I_{b}+\frac{\sigma_{s}}{4 \pi} \int_{0}^{4 \pi} I\left(\vec{r}, \overrightarrow{s^{\prime}}\right) \phi\left(\vec{s} \cdot \overrightarrow{s^{\prime}}\right) d \Omega^{\prime}-(a+ \\
& \left.\sigma_{s}\right) I(\vec{r}, \vec{s})
\end{aligned}
$$

The term $I_{b}$ describes the gain of intensity due to blackbody emission of medium where:

$$
I_{b}=n^{2} \frac{\sigma T^{4}}{\pi}
$$

Integrating equation 3 over control discrete angle, $\omega^{l}$

$$
\begin{aligned}
& \int_{w^{l}} \int_{S} I(s . n) d S d=\int_{\omega^{l}} \int_{V_{P}}\left[a I_{b}-\left(a+\sigma_{s}\right)+\right. \\
& \left.\frac{\sigma_{s}}{4 \pi} \int_{4 \pi} I \phi\left(\vec{s} \cdot \vec{s}^{\prime}\right) d \Omega^{\prime}\right] d V d \omega
\end{aligned}
$$

\subsubsection{Boundary condition}

For both the front and backsides of the PV module, we considered the radiation and convection losses, which can be expressed as follows:

Upper side:

$-k_{f} \frac{\partial T}{\partial t}=h_{f}\left(T_{a m b}-T_{f}\right)+\varepsilon_{f} F \sigma\left(T_{s k y}^{4}-T_{f}^{4}\right)$

Bottom side

$-k_{b} \frac{\partial T}{\partial t}=h_{b}\left(T_{a m b}-T_{b}\right)+\varepsilon_{b} F \sigma\left(T_{g r}^{4}-T_{b}^{4}\right)$

Soil temperature " $\mathrm{T}_{\mathrm{gr}}$ » was assumed to be equal to ambient temperature $\left\langle\mathrm{T}_{\mathrm{amb}} »\right.$. The temperature of the 
sky « $\mathrm{T}_{\text {sky }} »$ could be obtained in kelvin approximately by this equation [19].

$$
T_{s k y}(t)=T_{a m b}(t)-6
$$

The convection heat transfer coefficient of the module is related to the wind speed and could be calculated by the equation [20]:

$$
h_{i}=5.7+3.8 u_{i}
$$

This equation is valid for wind speed, $\mathrm{u}_{\mathrm{i}}$, up to $5 \mathrm{~m} / \mathrm{s}$. This equation is used previously by several researchers to calculate the heat transfer coefficient from the top of PV surface [21]

\subsubsection{Energy equation for PCM}

To analyze the PCM module, we considered the following assumptions [11]:

- The heat transfer mode in the PCM is pure conduction.

- The thermo-physical properties of PCM are constant and identical in the two phases.

- PCM is homogeneous and isotropic.

- The PCM is initially in solid phase

A material in phase transition, i.e. solid to liquid or liquid to solid, the energy conversion for constant thermo-physical properties of this material can be expressed in terms of temperature and total enthalpy as follows [12]:

The enthalpy formulation for a conduction controlled phase change can be written as [12]:

$$
\frac{\partial H}{\partial T}=\nabla \cdot(K \cdot \Delta T)
$$

$\mathrm{H}$ is related to the temperature in term of the local liquid fraction $f$ and latent heat $\mathrm{L}$ as

$$
H=\int_{T_{m}}^{T} \rho C_{p} d T+\rho f L
$$

Liquid fraction, $\mathrm{f}$, is calculated as:

$$
\left\{\begin{array}{ccc}
f=0 & \text { if } & T<T_{s} \\
f=1 & \text { if } & T>T_{l} \\
f=\frac{T-T_{s}}{T_{l}-T_{s}} & \text { if } & T_{s}<T<T_{l}
\end{array}\right.
$$

\subsection{Model Validation}

We validated the present study without and with PCM by our experimentally obtained results, and by a previous experimental study by Park et al. [22]. This comparative study shows that the results obtained with our thermal model are in good agreement with our experimental results (see Figure 4), also consistent with the results of Park et al. [22] as shown in Figure 5 in the case of a PV module without PCM. The validation of the temperature variation without PCM. The temperature variation of the PV module with $\mathrm{PCM}$ integration is calculated from the model and is compared with the study of Park et al. (2014), as shown in Figure 6. The results of the computer simulation were consistent with the results obtained by Park et al and the comparison between them verified the accuracy of the model.

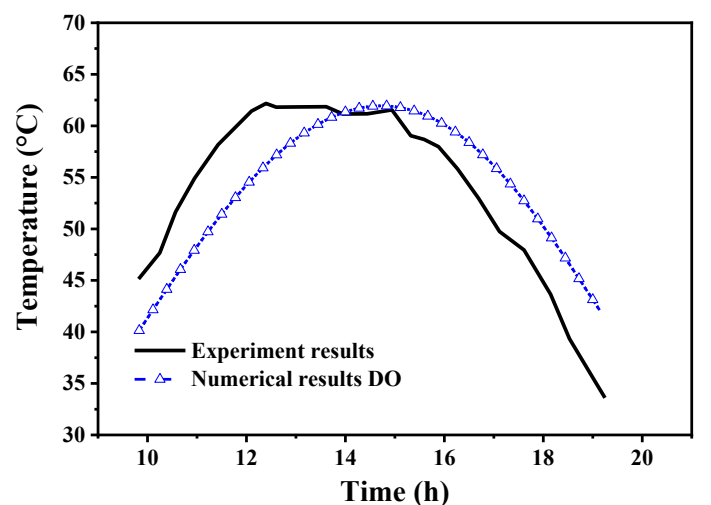

Figure 4. Comparison between measured temperature and simulation results

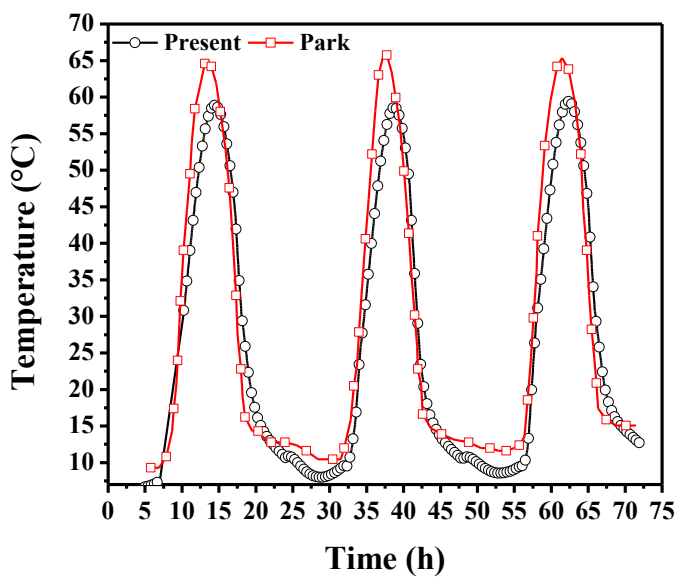

Figure 5. Model validation without PCM [22]

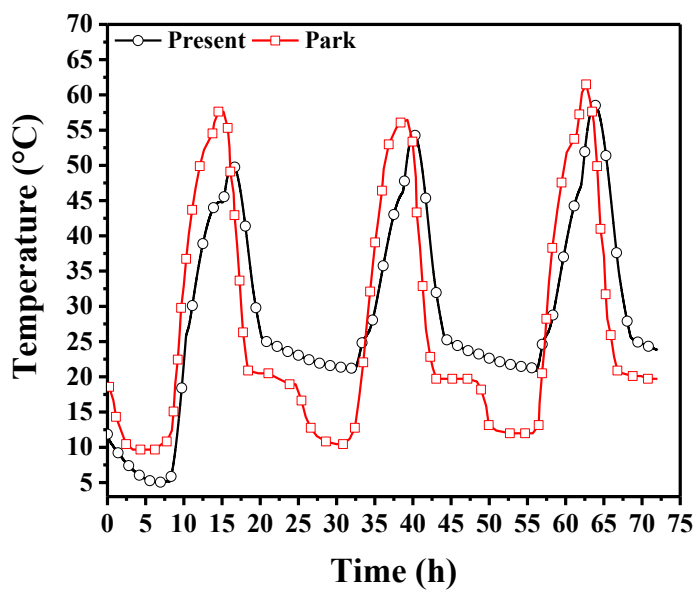

Figure 6. Model validation with PCM [22]

\section{Result and discussion}




\subsection{Temperature distribution in the PV module without PCM}

Figure 7 shows the temperature profile in the PV module at 14:10, which is the time when the PV module reaches its maximum operating temperature. The profile describes the temperature distribution from the first layer which is the glass to the Tedlar We note that the temperature increases with respect to the thickness of the PV module until reaching a maximum of $63,7{ }^{\circ} \mathrm{C}$ inside the solar cells, due to its high absorption, and the high transmissivity of the glass. Then the temperature begins to decrease at the level of the lower EVA located after the solar cell and Tedlar, which exchange the heat with the environment.

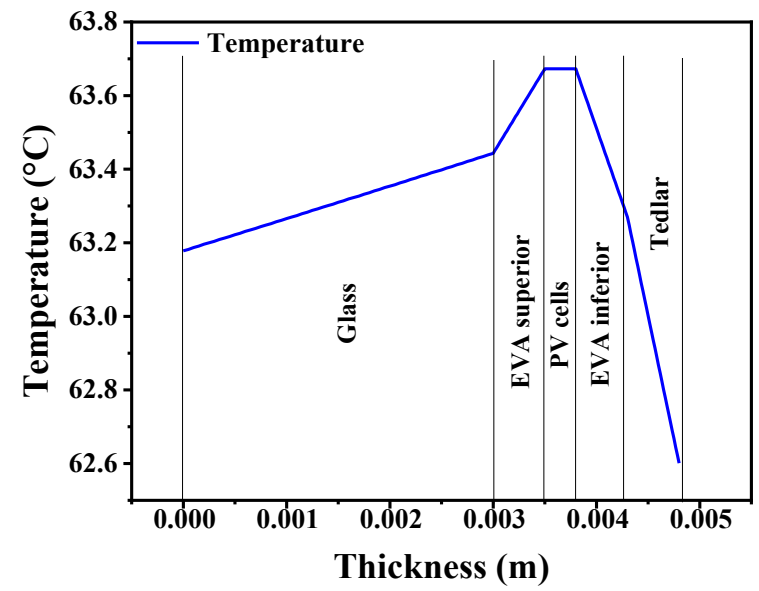

Figure 7. Temperature distribution profile within the PV module layers

The energy, which is not used for the production of electricity, is transformed into heat, due to the temperature difference between the layer of solar cell and the borders of the module would be transferred from solar cells to the front and back layers. The heat transfer varies according to the thermal resistance values of each layer listed in Table 4. The thermal resistance of the two layers, Tedlar and EVA inferior, located at the back of the solar cells is higher than those of glass and EVA superior located at the front of the solar cells. This difference in thermal resistance allows to the heat exchange of being very easy through the upper EVA and the glass, which is why we have the temperature of the glass, is higher than that of the Tedlar.

Table 4. Thermal resistance of each layer of PV module and Aluminium

\begin{tabular}{|l|l|}
\hline Material's layers & $\begin{array}{l}\text { Conduction thermal resistance } \\
\mathrm{m}^{2} \mathrm{~K} / \mathrm{W}\end{array}$ \\
\hline Glass & $16.666667 \times 10^{-4}$ \\
\hline EVA & $14.285714 \times 10^{-4}$ \\
\hline Polycrystalline silicon & $20.27 \times 10^{-7}$ \\
\hline Tedlar & $25 \times 10^{-4}$ \\
\hline Aluminum & $94.787 \times 10^{-7}$ \\
\hline
\end{tabular}

\subsection{Effect of integration of different PCM in the PV module with different thickness}

To reduce the temperature of the PV module, we tested two different types of PCMs, with different thermophysical properties.

Figure 8 shows the temperature evolution of the PV module without PCM, and after integration of the PCM. The two PCMs start to melt once their fusion temperature is reached, and consequently the temperature of the module begins to drop. As shown in Figure 8, the RT35HC begins its fusion at 9:00 am with a drop of temperature of $5 \pm 2^{\circ} \mathrm{C}$, and complete its fusion at 1:30 pm, while the RT44HC begins its fusion at 10:00 am and, complete its fusion at 13:30 am with a drop of temperature of $3 \pm 1^{\circ} \mathrm{C}$.

The moment when the PCM is completely melted, its liquid fraction is equal to 1 , we find that the temperature of the system begins to increase and, the temperature of the PV/PCM system exceeds the maximum temperature of the reference PV module. We consider that PCM in its liquid state acts as an insulator due to its low thermal conductivity.

From figure 8, 9 and 10, we see that by adding thickness, the time to store the energy as latent heat will be longer and, therefore, the temperature of the PVmodule will decrease as the thickness of the PCM layer increases.

If we evaluate the maximum temperature reached by the PV module, we find that the PCM RT44HC decreases the temperature of the $\mathrm{PV}$ module by $3^{\circ} \mathrm{C}$ for a thickness of $0.03 \mathrm{~m}$ better than the RT35HC. On the other hand, we find that the PCM RT35HC gives a lower temperature of the reference module and the module with RT44HC from 9:30 am to 3:40 pm. The PCM $\mathrm{RT} 35 \mathrm{HC}$ remains in its fluid state a longer time than the RT44HC, which allows it to increase the module temperature, which reaches almost to the reference module temperature.

We raise the thickness of the PCM again to $0.04 \mathrm{~m}$; we find that the PCM RT35HC gives better results than the PCM RT44Hc, with a drop in module temperature of $8^{\circ} \mathrm{C}$ compared to the reference module. For the RT44HC, it is important to note that it is not completely melted which indicates that there was an unused amount of PCM.

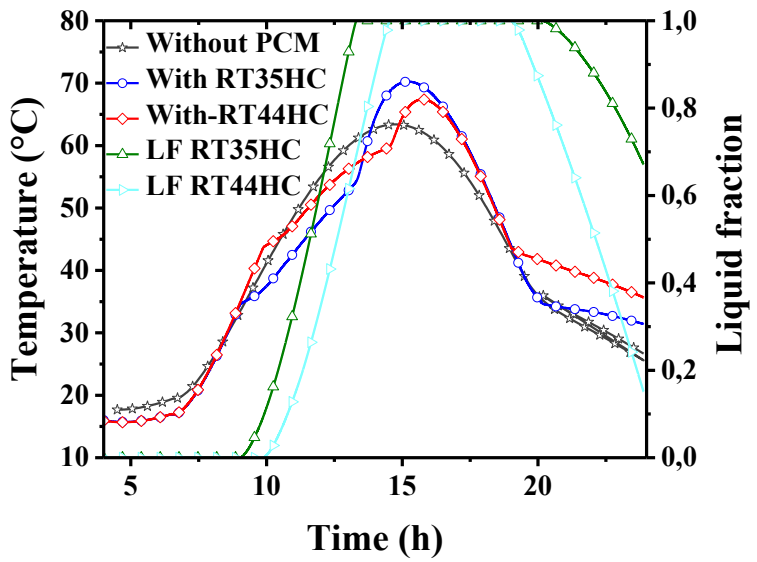

Figure 8. Temperature evolution for PV module coupled with two different PCM with thickness of $0.02 \mathrm{~m}$ 


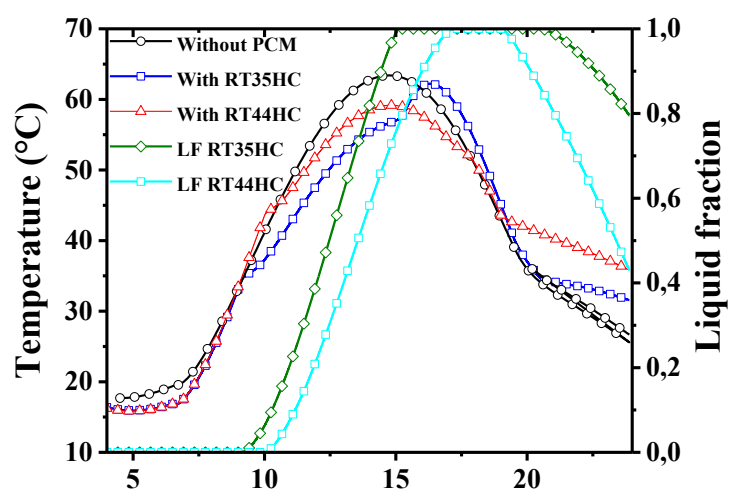

Time (h)

Figure 9. Temperature evolution for PV module coupled with two different PCM with thickness of $0.03 \mathrm{~m}$

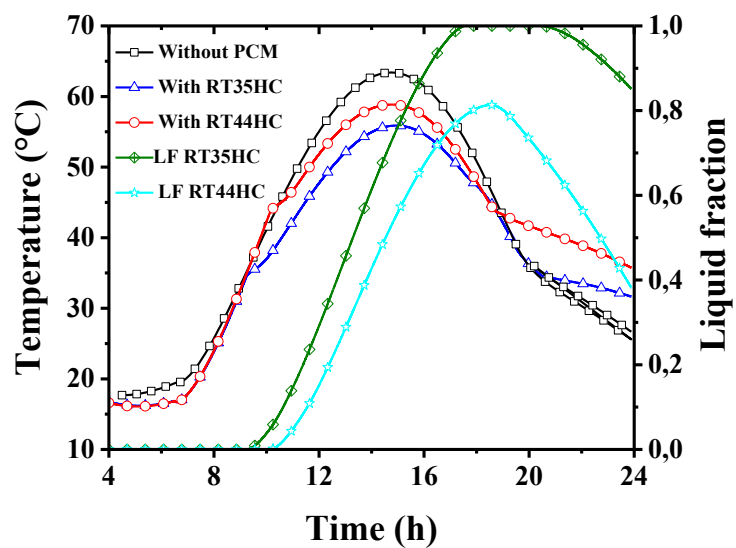

Figure 10. Temperature evolution for PV module coupled with two different PCM with thickness of $0.04 \mathrm{~m}$

\subsection{Latent heat effect}

In this section, we evaluate the effect of latent heat for a PCM RT35HC and RT35 with the same melting temperature and different latent heat. The thermophysical properties of RT35Hc are listed in Table 5.

From figure 11, we see that the RT35 PCM with a thickness of $0.04 \mathrm{~cm}$ coupled to the PV module gives an operating temperature exceeding that obtained with the RT35HC with the same thickness, which requires increasing the thickness of the PCM. As shown in Figure 11 , we increased the thickness of PCM RT35 to $0.06 \mathrm{~m}$ to have the temperature obtained by the PCM RT35HC, which implies latent heat to a non-negligible importance in a PCM. We conclude that latent heat has a significant effect on the PCM. The PCM RT35 having a latent heat is divided by 1.5 of that of $\mathrm{RT} 35 \mathrm{HC}$ requires a thickness of 1.5 of that of RT35HC to decrease the temperature of the module to the same level as RT35HC.

Table 5. Thermo-physical proprieties of PCM RT35

\begin{tabular}{|l|l|}
\hline PCM & RT35 \\
\hline Melting temperature $\left({ }^{\circ} \mathrm{C}\right)$ & 35 \\
\hline Density $\left(\mathrm{kg} / \mathrm{m}^{3}\right)$ & $860 \mathrm{~s} / 7701$ \\
\hline Specific heat $(\mathrm{J} / \mathrm{kg} \mathrm{K})$ & 2000 \\
\hline
\end{tabular}

\begin{tabular}{|l|l|}
\hline Latent heat & 160000 \\
\hline $\begin{array}{l}\text { Thermal conductivity (W/ m } \\
\mathrm{K})\end{array}$ & 0.2 \\
\hline
\end{tabular}

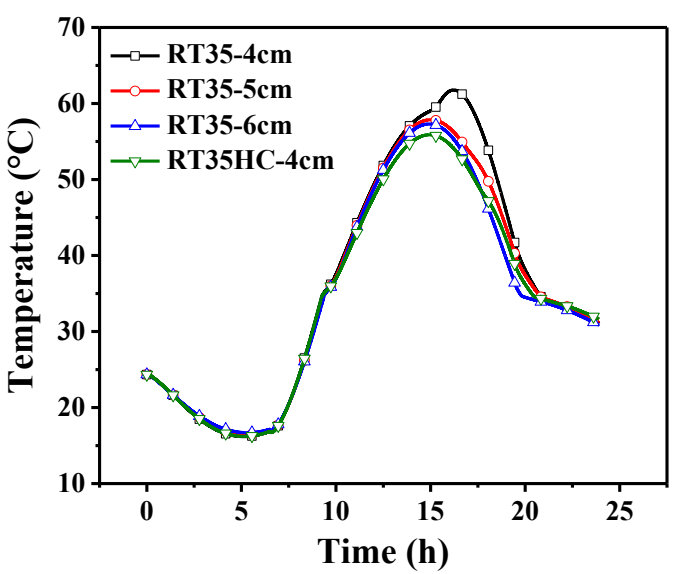

Figure 11. Temperature evolution for PV module for different thickness of PCM RT35

\subsection{Temperature distribution in the PV/PCM (RT35HC) system}

In this section, we discuss the temperature distribution profile in the PV / PCM (RT35HC) system.

From Figure 12, we notice that the maximum temperature difference of the PV/PCM system between the eastern back side and the front side reaches a maximum of $27^{\circ} \mathrm{C}$. In contrast to the $\mathrm{PV}$ module without PCM, we find that the difference between the maximum temperature of the front side and the back side are almost the same as shown in Figure 6 in Section 1.

Once the PCM begins its fusion we see that the temperature of rear face Begin to drop. We justify this result by: 1) the heat, which is concentrated at the level of the solar, cells when and dissipates in both directions, before it reaches the last layer; it would be absorbed by the PCM. 2) The aluminum back layer exchanges more heat with the environment because of its high conductivity.

In order to demonstrate the thermal behavior of the PCM integrated PV module, we choose the moment when the solar cells reach their maximum temperature, $3: 30 \mathrm{pm}$, and we plot the temperature profile along its thickness (see Figure $(13, a, b))$. Figure $(13, a)$ shows a temperature distribution profile from the glass where the sunlight enters to the first layer of aluminum, likewise Figure $(13, b)$ shows the temperature profile in the PCM and its aluminum boxing. 


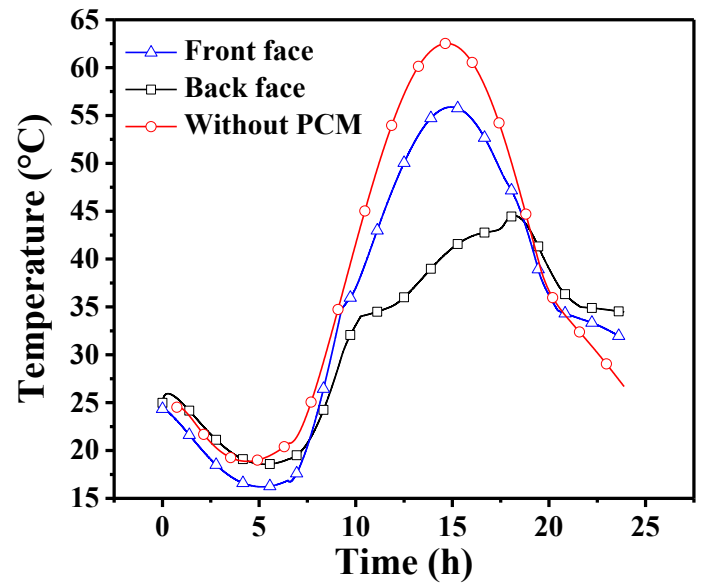

Figure 12. Temperature evolution in front and rear face of PV/PCM system

From figure $(13$, a) we notice that the maximum temperature is found at the front side, unlike the temperature profile of the PV module without PCM where the maximum temperature is reached by the solar cells.

When the cells dissipate heat, this last one propagates towards the front face more than the back face due to the low thermal resistance of the glass and the superior Eva. The heat dissipated towards the back before passing to the back face it would be absorbed by the PCM. This explains the difference in the profile of the temperature distribution between the PV module without and with PCM

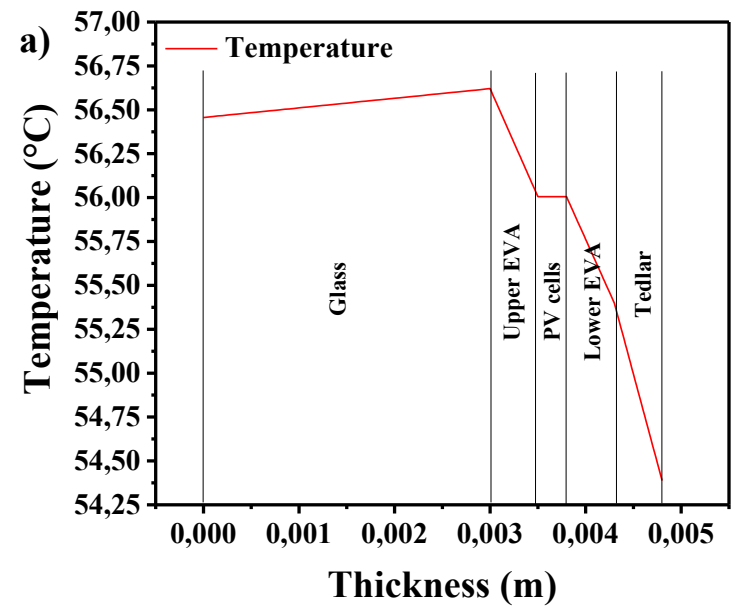

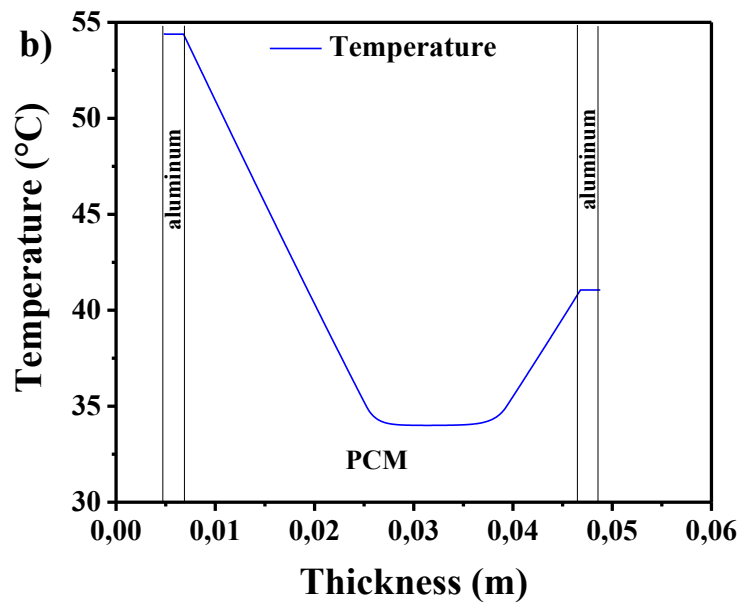

Figure 13. a) Temperature distribution profile for a PV module, b) Temperature distribution profile for the aluminum box and PCM

\section{Conclusion}

The PV module reaches a maximum temperature, which is equal to $63.7{ }^{\circ} \mathrm{C}$. The PCM cooling system was investigated to examine the effects on temperature reduction and thermal behavior of PV module in the Errachidia climate. Different PCMs are tested with different thickness, the results clearly show that PCM gives an effective way of regulating the increase in the operating temperature of PV module; we found also that the thickness of the PCM is an important parameter, which influences the thermal behavior of the PCM. The results of the study are synthesized below:

- The solar cell reaches the maximum temperature in the PVmodule

- The temperature distribution inside the PV module depends on thermal resistance of the layers

- $\mathrm{RT} 35 \mathrm{HC}$ decrease the temperature of the PV module by $8^{\circ} \mathrm{C}$ better than the RT44HC for one day

- Comparing RT35Hc and RT35, we find that the latent heat is a significant effect in thermal comportment of PCM, for the RT35 which have a low latent heat, it need to increase its thickness

- The thermal resistance of layers affects heat dissipated by the solar cell and absorbed by the PCM.

\section{Reference}

[1] E. Radziemska, "The effect of temperature on the power drop in crystalline silicon solar cells," Renew. Energy, vol. 28, pp. 1-12, 2003.

[2] A. Hasan, S. J. McCormack, M. J. Huang, and B. Norton, "Evaluation of phase change materials for thermal regulation enhancement of building integrated photovoltaics," Sol. Energy, vol. 84, no. 9, pp. 1601-1612, 2010.

[3] J. cheng Zhou, Z. Zhang, H. jian Liu, and Q. Yi, "Temperature distribution and back sheet role of polycrystalline silicon photovoltaic modules," 
Appl. Therm. Eng., vol. 111, pp. 1296-1303, 2017.

[4] A. M. Elbreki, M. A. Alghoul, K. Sopian, and T. Hussein, "Towards adopting passive heat dissipation approaches for temperature regulation of PV module as a sustainable solution," Renew. Sustain. Energy Rev., vol. 69, no. July, pp. 961-1017, 2017.

[5] H. G. Teo, P. S. Lee, and M. N. A. Hawlader, "An active cooling system for photovoltaic modules," Appl. Energy, vol. 90, no. 1, pp. 309315, 2012.

[6] A. Shukla, K. Kant, A. Sharma, and P. H. Biwole, "Cooling methodologies of photovoltaic module for enhancing electrical efficiency: A review," Sol. Energy Mater. Sol. Cells, vol. 160, no. July 2016, pp. 275-286, 2017.

[7] M. M. Farid, A. M. Khudhair, S. A. K. Razack, and S. Al-Hallaj, "A review on phase change energy storage: Materials and applications," Energy Convers. Manag., vol. 45, no. 9-10, pp. 1597-1615, 2004.

[8] A. Sharma, V. V. Tyagi, C. R. Chen, and D. Buddhi, "Review on thermal energy storage with phase change materials and applications," Renew. Sustain. Energy Rev., vol. 13, no. 2, pp. 318-345, 2009.

[9] M. C. Browne, B. Norton, and S. J. McCormack, "Phase change materials for photovoltaic thermal management," Renew. Sustain. Energy Rev., vol. 47, pp. 762-782, 2015.

[10] A. Hasan, S. J. McCormack, M. J. Huang, J. Sarwar, and B. Norton, "Increased photovoltaic performance through temperature regulation by phase change materials: Materials comparison in different climates," Sol. Energy, vol. 115, pp. 264-276, 2015.

[11] M. A. Kibria, R. Saidur, F. A. Al-Sulaiman, and M. M. A. Aziz, "Development of a thermal model for a hybrid photovoltaic module and phase change materials storage integrated in buildings," Sol. Energy, vol. 124, pp. 114-123, 2016.s

[12] V. R. Voller, "FAST IMPLICIT FINITEDIFFERENCE METHOD FOR THE ANALYSIS OF PHASE CHANGE PROBLEMS," Numer. Heat Transf., vol. 17, no. September 2012, pp. 155-169, 1990.

[13] V. R. Voller, "An implicit enthalpy solution for phase change problems: with application to a binary alloy solidification," Appl. Math. Model., vol. 11, no. 2, pp. 110-116, 1987.

[14] V. R. Voller, "An overview of numerical methods for solving phase change problems," Adv. Numer. heat Transf. Vol. 1, vol. 1, pp. 341-
$375,1997$.

[15] F. Agyenim, N. Hewitt, P. Eames, and M. Smyth, "A review of materials, heat transfer and phase change problem formulation for latent heat thermal energy storage systems ( LHTESS )," vol. 14, pp. 615-628, 2010.

[16] A. C. M.Sakami, "Application de la méthode des ordonnées discrètes au transfert radiatif dans un milieu bidimensionnel gris géomEtrie complexe," Sci. York, vol. 35, pp. 83-94, 1996.

[17] J. Y . Murthy and S. R. Mathur, "A finite volume scheme for radiative heat transfer in semitransparent media," Numer. Heat Trasfer,Parb B Fundam. An Int. J. Comput. Methodol., vol. 37, no. February 2014, pp. $25-$ 43, 2010.

[18] P. Chein and J. Hoi, "Validation of Discrete Ordinate Radiation Model for Application in UV Air Disinfection Modeling,” 2017.

[19] J. A. Duffie, W. A. Beckman, R. Winston, and F. Kreith, “ $\quad$ Solar-Energy Thermal Processes ," Phys. Today, vol. 29, no. 4, pp. 62-67, 1976. .

[20] M. Ahmed and A. Radwan, "Performance evaluation of new modified low-concentrator polycrystalline silicon photovoltaic/thermal systems," Energy Convers. Manag., vol. 149, no. May, pp. 593-607, 2017.

[21] M. Emam and M. Ahmed, "Cooling concentrator photovoltaic systems using various configurations of phase-change material heat sinks," Energy Convers. Manag., vol. 158, no. January, pp. 298-314, 2018.

[22] J. Park, T. Kim, and S. B. Leigh, "Application of a phase-change material to improve the electrical performance of vertical-buildingadded photovoltaics considering the annual weather conditions," Sol. Energy, vol. 105, pp. 561-574, 2014. 